\title{
Relationship between Plasma Endothelin-1 and Glycemic Control in Type 2 Diabetes Mellitus
}

\author{
S. S. Sánchez, M. J. Aybar, M. S. Velarde, M. M. Prado, T. Carrizo \\ Departamento de Biología del Desarrollo, INSIBIO, CONICET-UNT; and Cátedra de Práctica Hospitalaria (M.S.V., M.M.P, T.C.), \\ Facultad de Bioquímica, Química y Farmacia, Universidad Nacional de Tucumán, Tucumán, Argentina
}

\section{Introduction}

The pathogenesis of the vascular complications of diabetes is controversial, micro- and macroangiopathy being the most common cause of morbidity and mortality in diabetic patients. Endothelial cell damage, thought to occur in diabetic patients, may be an important factor in development of angiopathy $[1,2]$. For the last few years, considerable evidence has connected endothelin-1 (ET-1), a strong endothelial-derived vasoconstrictor mitogenic peptide, with various cardiovascular disease states [3].

Plasma ET-1 concentrations were found to be abnormally high in patients with conditions associated with endothelial cell injury, as well as in those with hypertension [4-6], congestive heart failure [7], coronary artery disease [8-10], and uremia [11]. Contradictory findings regarding ET-1 levels have been reported in patients suffering from diabetes mellitus [12-14]. Bertello et al. [14] and Kanno et al. [15] described similar plasma ET-1 levels in both healthy controls and patients with noninsulin-dependent diabetes mellitus (Type 2 diabetes) with and without complications. However, the influence of Type 2 diabetes on plasma endothelin levels was definitely established in patients with advanced atherosclerosis [16]. Recent clinical studies have indicated that the normalization of glycemic control cannot only prevent diabetic microangiopathies, but might possibly avert cardiovascular complications [17], thus pointing to hyperglycemia as the major causal factor in the development of diabetic vascular complications. Moreover, there are indications that high blood glucose is involved in the pathogenesis of coronary heart disease, being a significant factor in cardiovascular mortality $[18,19]$. However, in spite of the significant effects of hyperglycemia, very few studies have dealt with the possible influence of glucose metabolic control on endothelial reactivity in Type 2 diabetic patients.

The aims of the present paper were a) to establish the possible relationship between plasma ET-1 levels and Type 2 diabetes by comparing plasma ET-1 concentrations in healthy subjects with those in patients with uncomplicated Type 2 diabetes and b) to determine whether ET-1 levels were related to glucose metabolic control in diabetic patients.

\section{Material and Methods}

We measured the circulating ET- 1 concentration in 44 Type 2 diabetic patients ( 25 men and 19 women, aged $53.4 \pm 8.8$ ) from the Hospital Centro de Salud (San Miguel de Tucumán, Tucumán, Argentina) and in 40 healthy volunteers who formed the control group, whose ages matched those of the patients (20 men and 20 women, aged $46.7 \pm 10.7$ ). The control group had no history of major diseases, was taking no medication, not even hormonal contraceptives, and had no family background of diabetes mellitus. All subjects were evaluated to determine their body mass index (BMI) and lipid profiles and also the duration of diabetes and the levels of hemoglobin A1c (HbA1c) in the diabetic patients. None of the diabetic patients were smokers or drinkers; they did not suffer from hypertension (blood pressure $<140 / 90 \mathrm{mmHg}$ ), evident renal dysfunction (serum creatinine levels $<110 \mathrm{mmol} / \mathrm{l}$; microalbuminuria $<20 \mathrm{mg} /$ day) or diabetic retinopathy, nor did they exhibit altered lipid profiles or signs of macrovascular disease. These patients were divided into two groups (according to their glycemic control): a) with good glycemic control (HbA1c $\leq 7.00 \%)$ and b) with poor glycemic control (HbA1c $>7.00 \%$ ). Throughout the study, they were given no drugs except for oral hypoglycemic agents (all patients were treated with sulfonylureas, and had taken the last dose of the antidiabetic drugs the night before). After the patients had fasted overnight, blood samples were drawn from the antecubital vein into tubes containing EDTA and aprotinin, after at least 15 minutes of sitting rest. The samples were centrifuged at $4{ }^{\circ} \mathrm{C}$, and plasma was frozen immediately at $-20^{\circ} \mathrm{C}$ until assayed. After extracting the plasma, endothelin was determined using a highly specific solidphase ELISA method for human ET-1 (R\&D Systems, Inc., Minneapolis, MN, USA, catalog number BBE5). The extraction procedures in the preparation of samples yielded a recovery of $95 \%$, and intra-inter-assays were $4.5 \%$ and $5.5 \%$, respectively. In all subjects, HbA1c was measured with an Abbott IMX autoanalyzer (ICIA method). Microalbuminuria was determined 
Table 1 Clinical characteristics and laboratory parameters of diabetic patients and control subjects

\begin{tabular}{|c|c|c|c|}
\hline & \multirow[b]{2}{*}{ Control subjects } & \multicolumn{2}{|c|}{ Diabetic patients } \\
\hline & & Good glycemic control & Poor glycemic control \\
\hline$N(\mathrm{M} / \mathrm{F})$ & $40(20 / 20)$ & $14(7 / 7)$ & $30(18 / 12)$ \\
\hline Age & $46.6 \pm 10.7$ & $57.7 \pm 7.1$ & $51.7 \pm 9.1$ \\
\hline Known diabetes duration (years) & - & $8.0 \pm 5.2$ & $9.1 \pm 9.0$ \\
\hline HbA1c (\%) & $5.59 \pm 0.45$ & $5.89 \pm 0.54$ & $9.92 \pm 2.35^{*}$ \\
\hline Body mass index $\left(\mathrm{kg} / \mathrm{m}^{2}\right)$ & $24.65 \pm 2.50$ & $28.55 \pm 3.05+$ & $30.22 \pm 7.00+$ \\
\hline Systolic blood pressure $(\mathrm{mmHg})$ & $124.2 \pm 8.1$ & $128.4 \pm 3.2$ & $129.4 \pm 7.7$ \\
\hline Diastolic blood pressure $(\mathrm{mmHg})$ & $77.8 \pm 3.3$ & $80.4 \pm 3.7$ & $78.1 \pm 2.5$ \\
\hline Fasting glucose (mmol/l) & $4.70 \pm 0.50$ & $6.25 \pm 2.10^{* *}$ & $9.50 \pm 6.39^{*}$ \\
\hline Fasting insulin (pmol/l) & $72.15 \pm 34.50$ & $82.20 \pm 42.25$ & $76.8 \pm 28.60$ \\
\hline Triglyceride (mg/dl) & $97.30 \pm 15.7$ & $139.80 \pm 48.25$ & $175.10 \pm 115.20$ \\
\hline Total cholesterol (mmol/l) & $4.65 \pm 0.30$ & $4.50 \pm 1.05$ & $4.65 \pm 1.20$ \\
\hline HDL-cholesterol (mmol/l) & $1.25 \pm 0.10$ & $1.20 \pm 0.15$ & $1.06 \pm 0.30$ \\
\hline LDL-cholesterol (mmol/l) & $2.85 \pm 0.30$ & $2.90 \pm 0.95$ & $3.20 \pm 1.15$ \\
\hline Fibrinogen (mg/dl) & $250.25 \pm 38.00$ & $313.30 \pm 54.05$ & $348.75 \pm 79.50$ \\
\hline
\end{tabular}

Data are mean \pm S.D.; $\left({ }^{*}\right) \mathrm{p}<0.00001$ poor glycemic control vs. control subjects. $\left({ }^{* *}\right) \mathrm{p}<0.005$ good glycemic control vs. control subjects. $(+) \mathrm{p}<0.0005$ poor glycemic control and good glycemic control vs. control subjects.

using Micral-Test II (Boehringer Mannheim GmbH, Mannheim, Germany) reactive strips. Plasma insulin levels were determined by means of the Abbott IMX (MEIA method). All chemical tests were performed using standard laboratory methods.

\section{Statistical analysis}

Results were expressed as the mean \pm S.E.M. Statistical evaluation was performed using Student's $t$-test for parametric data, and differences between groups were analyzed by one-way analysis of variance. A simple linear regression analysis was used to evaluate the correlation between the two parameters. Statistical significance was assumed at $\mathrm{p}<0.05$.

\section{Results}

Clinical characteristics and laboratory details from both diabetic patients and normal control subjects are summarized in Table 1. Type 2 diabetic patients showed increased plasma triglycerides, fibrinogen and fasting glucose blood levels compared to normal controls. On the basis of glycemic control, diabetic patients were classified into two groups: a good glycemic control group (HbA1c $\leq 7.00 \%)$ and a poor glycemic control group (HbA1c $>7.00 \%$ ). The group of diabetic patients with good glycemic control did not show any significant differences in mean HbA1c concentration compared to normal control subjects $(p=0.3121)$. In contrast, noticeable differences in mean HbA1c concentration were found when comparing diabetic patients with poor glycemic control to normal control subjects $(\mathrm{p}<0.00001)$.

Values for BMI $(\mathrm{p}=0.4967)$, systolic blood pressure $(p=0.7980)$, diastolic blood pressure $(p=0.2899)$, glucose $(p=0.070)$, insulin $(p=0.7253)$, triglycerides $(p=0.2790)$, total cholesterol $(p=0.2795)$, HDL-cholesterol $(p=0.1995)$, LDL-cholesterol $(\mathrm{p}=0.3683)$ and fibrinogen $(\mathrm{p}=0.1385)$ did not significantly differ between the two diabetic groups, and

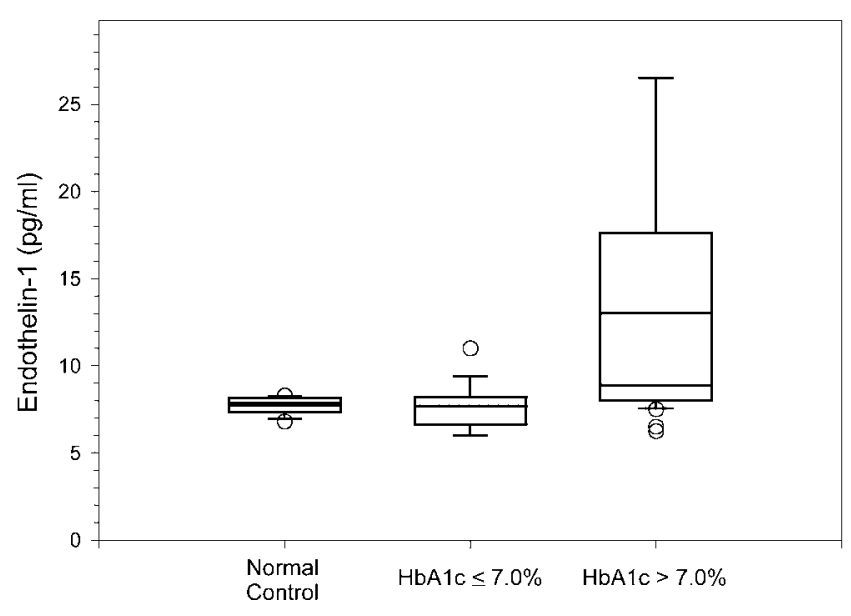

Fig. 1 Plasma ET-1 concentrations in diabetic and control subjects. Boxes represent 25th and 75 th percentiles, with the median as the horizontal line inside the box. The 10th and 90th percentiles are shown by the horizontal lines below and above the boxes.

neither did other factors, such as liver and renal functions (data not shown).

The mean plasma ET- 1 concentration in 44 diabetic patients was $11.32 \pm 6.76 \mathrm{pg} / \mathrm{ml}$ compared to $7.72 \pm 0.50 \mathrm{pg} / \mathrm{ml}$ in normal subjects, these values being significantly different $(p<0.001)$. When diabetic patients were divided into two groups (Fig. 1) according to glycemic control, the plasma level of ET-1 in the poor glycemic control group was significantly higher than that in the good glycemic control group $(13.03 \pm 7.57 \mathrm{pg} / \mathrm{ml}$ vs. $7.64 \pm 1.40 \mathrm{pg} / \mathrm{ml}, \mathrm{p}<0.01)$. There were no significant differences between the Type 2 diabetic patients with good glycemic control and normal control subjects in the plasma ET-1 level ( $p=0.848$ ). On the other hand, there was a significant difference in the plasma ET-1 levels in the poor gly- 


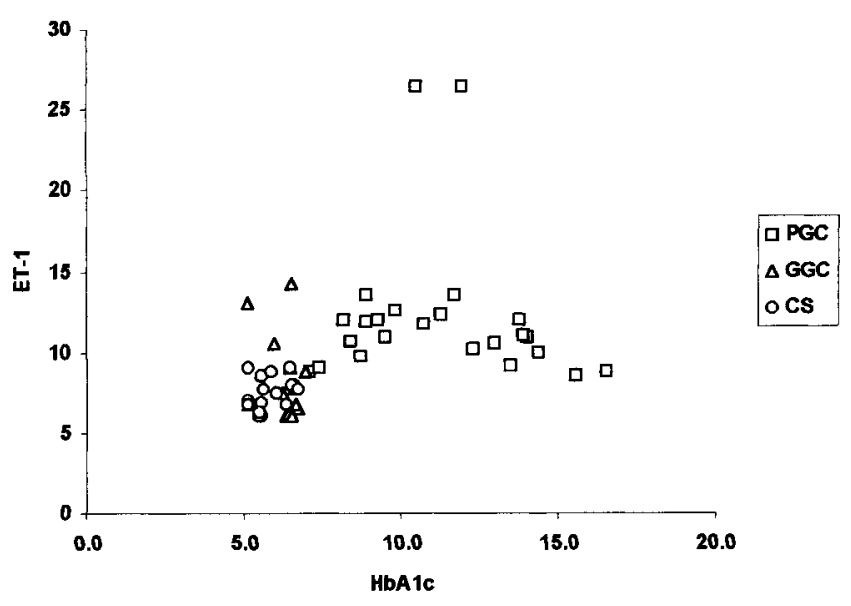

Fig. 2 Relationship between HbA1c and basal circulating ET-1 levels in Type 2 diabetes mellitus. PGC (poor glycemic control) $r=-0.10$; GGC (good glycemic control) $r=-0.28$; CS (control subjects) $r=0.39$.

cemic control group compared to the normal control group $(\mathrm{p}<0.001)$.

Fig. 2 shows ET-1 levels plotted against HbA1c concentrations for the total study population and within subgroups. No correlation was found between ET-1 and HbA1c levels in any of the groups studied - good glycemic control group $(r=-0.28)$, poor glycemic control group $(r=-0.10)$, compared to the normal control group $(r=0.39)$. When ET-1 concentrations were compared with actual plasma glucose levels, no correlation was found in any of the groups studied - good glycemic control group ( $r=0.39$ ), poor glycemic control group $(r=0.01)$ compared to normal control subjects group $(\mathrm{r}=-0.25)$.

\section{Discussion and Conclusions}

This study shows that plasma ET-1 levels in patients suffering from Type 2 diabetes are not similar to those found in healthy subjects. In fact, the diabetic population's plasma ET-1 levels were higher than the normal control range, the difference being statistically significant. Although our results agree with the observations made by Takahashi et al. [12] and Letizia et al. [20] who found that plasma ET-1 levels are significantly elevated in the diabetic patients compared with the healthy subjects, they disagree with those of Predel et al. [21] and Tsumoda et al. [22], who reported that ET-1 levels were in the same range in both healthy and diabetic subjects.

In our studies, the ET-1 level of patients with poor glycemic control was significantly higher than in the group with good glycemic control when the diabetic population was grouped according to glycemic control, which agrees with the findings of Haak et al. [13]. However, even though these authors reported that ET-1 levels were correlated with metabolic control and disease duration in diabetic patients, no correlation was found either between ET-1 and HbA1c or between ET-1 and glucose in our study. In any case, our findings would suggest the importance of glycemic control in diabetic patients in concordance with the results of the Diabetes Control and Complications Trial (DCCT) [23].
Increased oxidative stress has been determined in diabetes [24], the production of free radicals having been correlated with metabolic control and, more directly, with hyperglycemia [25]. Yamauchi et al. [26] reported that the release of ET-1 by cultured bovine endothelial cells is stimulated by high glucose concentrations in the culture medium, a fact that suggests that glucose-stimulated ET-1 release might be involved in the development of vascular complications in diabetes. According to the above, sustained poor metabolic control would lead to the development of an altered endothelial function, while hyperglycemia might probably determine the onset of endothelial alteration.

Altered endothelial function is regarded as an early sign of vascular disease that develops even before clinical signs, such as hypertension or vasculopathy, have become evident. In a similar way, Stroes et al. [27] demonstrated endothelial dysfunction with impaired endothelium-dependent vasodilatation in hypercholesterolemic patients at risk for atherosclerosis but without evident arterial disease.

It has been recognized that hyperinsulinemic states, such as Type 2 diabetes, are associated with an accelerated vascular disease [28]. Hu et al. [29] recently demonstrated that insulin can markedly stimulate both the secretion of the ET-1 peptide and the transcription of the ET-1 mRNA in cultured endothelial cells. Also, Wolpert et al. [30] showed that the circulating levels of ET-1 in obese women increased after the induction of physiological hyperinsulinemia and decreased with weight reduction in direct relation with changes in insulin levels. As regards Type 2 diabetes patients, it has been suggested that ET- 1 release might be stimulated merely by the consequent increase in insulin secretion. In our study, insulin levels were similar in the three groups under study: the poor glycemic control group, the good glycemic control group, and the healthy control group, so that increased ET-1 levels in the first group cannot be attributed to increased insulin levels.

Our findings support the hypothesis that plasma ET-1 levels are enhanced in patients with poor glycemic control and could play an important pathogenetic role in diabetes development. However, it must also be taken into account that increased plasma ET-1 levels would imply widespread alterations in the endothelial function in the vascular system in Type 2 diabetic patients.

\section{References}

${ }^{1}$ Kannel WB, McGee DL. Titel fehlt. JAMA 1979; 241: 2035-2038

2 Porta M, Selva ML, Molinatti P, Molinatti GM. Diabetologia 1987; 30: $601-609$

${ }^{3}$ Hofner RL, Gopalakrishnan V. Diabetologia 1999; 42: 1383-1394

${ }^{4}$ Saito Y, Nakao K, Mukoyama M, Imura H. N Engl J Med 1990; 322: 205

${ }^{5}$ Naruse M, Kaanna M, Hifumi S, Naruse K, Yoshiara I, Oka T. J Cardiovasc Pharmacol 1991; 17: S471 - S474

${ }^{6}$ Letizia C, Cerci S, D’Ambrosio C, Scuro L, Scavo D. J Hum Hypertens 1995; 9: $903-907$

${ }^{7}$ Stewart DJ, Cernacek P, Costello KB, Rouleau JL. Circulation 1992; 85: $510-517$

${ }^{8}$ Miyauchi T, Yangisawa M, Tomizawa T, Sugushita Y, Suzuki N, Fusino M, Ajisaka R, Goto K, Masaki T. Lancet 1989; 2: 53-54

${ }^{9}$ Yasuda M, Kohno M, Tahara A, Tagane H, Toda I, Akioka K, Teragaki M, Oku H, Takeuchi K, Takeda T. Am Heart J 1990; 119: 801 
${ }^{10}$ Letizia C, Barilla F, Cerci S, D’Ambrosio C, Coassin S, De Ciocchis A, Mastroiani MA, Campa PP, Scavo D. Angiology 1995; 46: 819826

${ }^{11}$ Masaoka H, Suzuki R, Hirata Y. Lancet 1989; 1: 991

${ }^{12}$ Takahashi K, Ghatei MA, Lam HC, O'Halloran DJ, Bloom SR. Diabetologia 1990; 33: 306-310

${ }^{13}$ Haak T, Jungmann E, Felber A, Hillmann U, Usadel KH. Am J Hypertens 1992; 5: $161-166$

14 Bertello P, Veglio F, Pinna G, Gurioli L, Molino P, Alban S, Chiandussi L. Diabetes Care 1994; 17: 574-577

${ }^{15}$ Kanno K, Hirata Y, Shichiri M, Marumo F. J Cardiovasc Pharmacol 1991; 17 (Suppl. 7): S475 - S476

16 Perfetto F, Tarquini R, Tapparini L, Tarquini B. J Diab Complic 1998; $12: 187-192$

17 The diabetes control and complications trial research group. The effect of intensive treatment of diabetes on the development and progression of long-term complications in insulin-dependent diabetes mellitus. N Engl J Med 1993; 329: 977-987

18 Klein R. Diabetes Care 1995; 18: 258-268

${ }^{19}$ Wei M, Gaskill SP, Haffner SM, Stern MP. Diabetes Care 1998; 21 : $1167-1172$

${ }^{20}$ Letizia C, Iannacone A, Cerci S, Santi G, Cilli M, Coassin S, Pannarale MR, Scavo D. Horm Metab Res 1997; 29: 247-251

${ }^{21}$ Predel HG, Meyer-Lelmert H, Baker A, Stelkens H, Kramer HJ. Life Sci 1990; 47: 1837-1843

22 Tsumoda K, Abe K, Yoshinaga K. J Hypertens 1992; 10 (Suppl. 4): S98

${ }^{23}$ Summers LKM, Clark ML, Humphreys SM, Bugler J, Frayn KN. Horm Metab Res 1999; 31: 424-428

${ }^{24}$ Telci A, Cakatay U, Kayah R, Erdogan C, Orhan Y, Sivas A, Akcay T. Horm Metab Res 2000; 32: 40-43

${ }^{25}$ Ceriello A, Giugliano D, Quatraro A, Dello Russo P, Lefebvre PJ. Diabetic Med 1991; 8: 540-542

${ }^{26}$ Yamauchi T, Ohnaka K, Takayanagi R, Umeda F, Nawata H. FEBS Lett 1990; 267: 16-18

${ }^{27}$ Stroes ESG, Koomans HA, de Bruin TWA, Rabelink TJ. Lancet 1995; 346: $467-471$

${ }^{28}$ Krolewski AS, Warram JH, Valsania P, Martin BL, Laffel LMB, Christlieb R. Am J Med 1991; 90 (Suppl 2A): 56-61

${ }^{29}$ Hu RM, Levin ER, Pedram A, Frank HJL. Diabetes 1993; 42: 351 358

${ }^{30}$ Wolpert HA, Steen SN, Istfan NW, Simonson DC. Metab Clin Exp 1993; 8: $1207-1230$
Requests for reprints should be addressed to:

Sara S. Sánchez

Depto. Biología del Desarrollo INSIBIO (CONICET-UNT)

Chacabuco 461

4000-San Miguel de Tucumán

Argentina

Phone: +54 (381) 4247752 ext. 358

Fax: $\quad+54(381) 4248025$

E-mail: ssanch@unt.edu.ar 